\title{
Advances in the delivery of RNA therapeutics: from concept to clinical reality
}

\author{
James C. Kaczmarek ${ }^{1,2 \dagger}$, Piotr S. Kowalski ${ }^{2 \dagger}$ and Daniel G. Anderson ${ }^{1,2,3,4^{*}}$
}

\begin{abstract}
The rapid expansion of the available genomic data continues to greatly impact biomedical science and medicine. Fulfilling the clinical potential of genetic discoveries requires the development of therapeutics that can specifically modulate the expression of disease-relevant genes. RNA-based drugs, including short interfering RNAs and antisense oligonucleotides, are particularly promising examples of this newer class of biologics. For over two decades, researchers have been trying to overcome major challenges for utilizing such RNAs in a therapeutic context, including intracellular delivery, stability, and immune response activation. This research is finally beginning to bear fruit as the first RNA drugs gain FDA approval and more advance to the final phases of clinical trials. Furthermore, the recent advent of CRISPR, an RNA-guided gene-editing technology, as well as new strides in the delivery of messenger RNA transcribed in vitro, have triggered a major expansion of the RNA-therapeutics field. In this review, we discuss the challenges for clinical translation of RNA-based therapeutics, with an emphasis on recent advances in delivery technologies, and present an overview of the applications of RNA-based drugs for modulation of gene/protein expression and genome editing that are currently being investigated both in the laboratory as well as in the clinic.
\end{abstract}

Keywords: Antisense oligonucleotide, Clinical trial, CRISPR, Gene editing, Gene therapy, Messenger RNA delivery, mRNA vaccine, RNA nanoparticle, Short interfering RNA delivery

\section{Background}

Fourteen years after the completion of the human genome project, our understanding of human genomics continues to develop at an unprecedented rate. Thanks to advances in next-generation sequencing technology, scientists have been able to identify the genetic roots of many common diseases [1]. Diseases such as cancer [2], Parkinson's [3], rheumatoid arthritis [4], and Alzheimer's [5] have all had many of their genetic components revealed, bringing us closer than ever to 'personalized medicine' [6]. Thus far, this knowledge has been well adapted for diagnostic use-but has not yet been fully translated to pharmaceutical interventions addressing the genetic defects underlying diseases. Currently, the two major structural classes of FDA-approved drugs are small molecules and proteins [7]. Small-molecule drugs,

\footnotetext{
* Correspondence: dgander@mit.edu

${ }^{\dagger}$ Equal contributors

${ }^{1}$ Department of Chemical Engineering, Massachusetts Institute of Technology, Cambridge, Massachusetts 02139, USA

${ }^{2}$ David H. Koch Institute for Integrative Cancer Research, Massachusetts

Institute of Technology, Cambridge, Massachusetts 02139, USA

Full list of author information is available at the end of the article
}

which consist predominantly of hydrophobic organic compounds, typically act by deactivating or inhibiting target proteins through competitive binding. However, the proteins that might possess such binding pockets have been estimated to account for only $2-5 \%$ of the protein-coding human genome [8]. Protein-based drugs (e.g., antibodies), by contrast, can bind with high specificity to a variety of targets or be used to replace mutated or missing proteins (e.g., delivering insulin for diabetes). However, the size and stability of proteins limit their utility towards many potential disease targets [7]. Thus, true realization of the therapeutic potential of personalized genomics requires treatments beyond those offered by current small-molecule and protein therapies.

In summary, both protein and small-molecule drugs are limited in that they cannot target every diseaserelevant protein or gene. The mRNA and DNA precursors of proteins, however, are promising therapeutically in that they can be specifically targeted via WatsonCrick base pairing and, in the case of gene editing, which aims to permanently change the host's DNA, represent an avenue to cure a genetic defect as opposed to 
just treating it. Over the past few decades, RNA drugs have emerged as candidates to address diseases at the gene and RNA levels. Although it has been known since 1990 that nucleic acids can be used to modulate protein production in vivo [9], therapeutic RNA delivery has been limited by a number of factors. Naked, singlestranded RNA is prone to nuclease degradation, can activate the immune system, and is too large and negatively charged to passively cross the cell membrane-and must, therefore, be provided with additional means of cellular entry and escape from endosomes, which transport extracellular nanoparticles into the cytoplasm [10]. As such, the nucleic acid delivery field has centered on the design of delivery methods and materials that will transport RNA drugs to the site of interest. In this review, we provide an overview of the current status of advances in RNA and RNA-protein therapy, with an emphasis on materials that have been developed for RNA delivery and applications of RNA-based drugs for the modulation of gene/protein expression and gene editing.

\section{Delivery materials and chemical modifications for RNA}

\section{Delivery materials}

Broadly speaking, RNA delivery can be mediated by viral and non-viral vectors. For viral RNA delivery, there has been a great deal of interest in engineering adenoassociated viruses to carry nucleic acid cargo [11] - however, this section will focus mainly on the development of non-viral materials (Table 1). Of the non-viral RNA delivery vehicles, nanoparticles are perhaps the most studied. Nanoparticle encapsulation of RNA physically protects nucleic acids from degradation and, depending on the specific chemistry, can aid in cellular uptake and endosomal escape. Given their high degree of chemical flexibility, polymers are commonly used materials for nanoparticle-based delivery [12]. Typically, cationic polymers are used to electrostatically condense the negatively charged RNA into nanoparticles (Fig. 1a) [13].
These positively charged groups often consist of amines that become protonated at physiological $\mathrm{pH}(\mathrm{pKa} \sim 7.4)$, thought to lead to an ion imbalance that results in endosomal rupture [14, 15], although this so-called 'proton sponge' hypothesis has yet to be rigorously demonstrated for various materials [16]. Regardless of the exact mechanism by which polymers aid in RNA delivery, commercially available amine-containing polymers were some of the earliest non-viral materials adopted for nucleic acid delivery. Synthetic polymers such as poly-Llysine [17], polyamidoamine [18], and polyethyleneimine [19], as well as naturally occurring polymers such as chitosan [20], have all been applied to RNA delivery, with varying levels of success. In addition, some investigators have synthesized polymers specifically for nucleic acid delivery. Poly( $\beta$-amino esters $)$, in particular, have gained widespread use in DNA delivery owing to their ease of synthesis and biodegradability [21], but have also proved to be capable of effecting delivery of short interfering RNA (siRNA) [22-24] and mRNA [25].

Lipids and lipid-like materials represent the second major class of nanoparticle-based delivery vehicles for RNA. As with polymers, cationic lipids are often used to electrostatically bind the nucleic acid. Many laboratories, however, have started utilizing ionizable lipids, which are lipids that are positively charged only at acidic $\mathrm{pH}$. This ionizable behavior is thought to enhance efficacy through helping with endosomal escape [26] and reducing toxicity [27] as compared with particles that remain cationic at physiological pH. Lipids are also capable of self-assembly into well-ordered nanoparticle structures, known as lipoplexes (Fig. 1b), driven by a combination of electrostatic interactions with RNA and hydrophobic interactions $[28,29]$. Optimizing the formulation of lipid nanoparticles (LNPs) by addition of other hydrophobic moieties, such as cholesterol and PEG-lipid, in addition to an ionizable/cationic lipid, enhances nanoparticle stability and can significantly enhance efficacy of RNA delivery [30]. However, similarly to polymers, it was found that ionizable lipid structure is the main factor

Table 1 Comparison of clinically relevant RNA delivery platforms

\begin{tabular}{|c|c|c|c|c|}
\hline Delivery vehicle & Type of RNA in clinical trials & Advantages & Disadvantages & References \\
\hline Naked RNA & siRNA, ASO, mRNA & $\begin{array}{l}\text { No additional materials or } \\
\text { synthesis required }\end{array}$ & $\begin{array}{l}\text { Prone to degradation } \\
\text { Immunogenic } \\
\text { Difficulty entering cell } \\
\text { Poor circulation half-life }\end{array}$ & {$[63-65,73-78,101,103,114,115$} \\
\hline Nanoparticle & siRNA, ASO, mRNA & $\begin{array}{l}\text { Increased half life } \\
\text { Protection from nucleases } \\
\text { Aids in endocytosis and } \\
\text { endosomal escape }\end{array}$ & $\begin{array}{l}\text { Elevated risk of toxicity with } \\
\text { introducing excipient materials }\end{array}$ & $\begin{array}{l}{[12-37,58-60,82-85,106-108} \\
110-113,131,145,156-159]\end{array}$ \\
\hline Conjugate & siRNA, ASO & $\begin{array}{l}\text { Defined chemical structure } \\
\text { Ability to target specific receptors } \\
\text { Limited toxicity due to lack of } \\
\text { excipient materials }\end{array}$ & $\begin{array}{l}\text { High doses required } \\
\text { Dependent on chemical } \\
\text { modifications for RNA stability }\end{array}$ & {$[38-43,62]$} \\
\hline
\end{tabular}


a

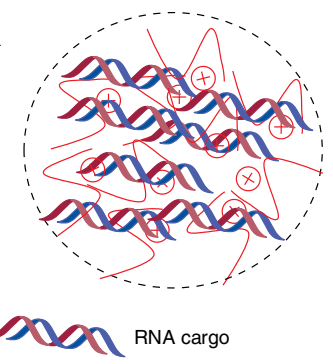

b

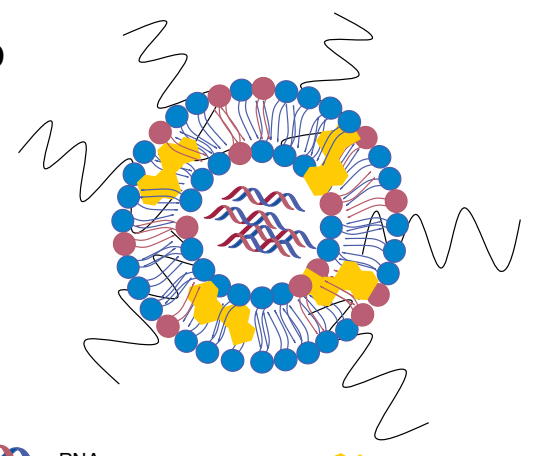

Cholesterol

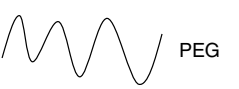

Cationic/ionizable lipid

C

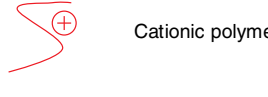

200 RnA cargo

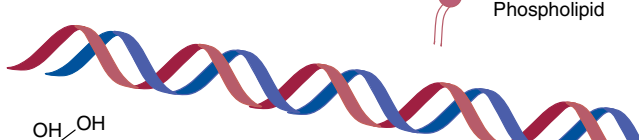

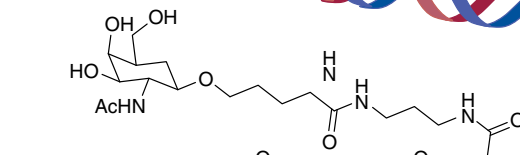

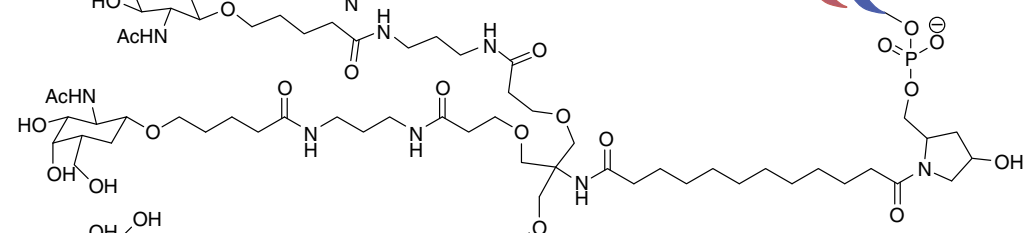

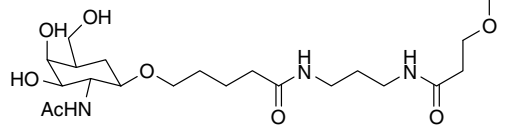

d

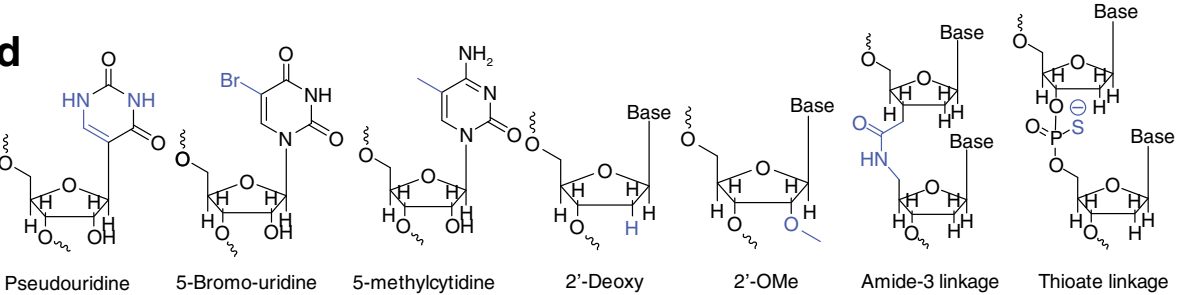

Fig. 1 Common delivery modalities for RNA. a Schematic depicting polymeric nanoparticles comprising RNA and cationic polymer. b Schematic depicting lipid nanoparticles containing RNA, a cationic/ionizable lipid, and other hydrophobic moieties (such as cholesterol) commonly used in nanoparticle formulation. c Chemical structure of a tertiary conjugate between $\mathrm{N}$-acetylgalactosamine (GalNAc) and RNA that is currently in clinical trials [38]. $\mathbf{d}$ Examples of base, sugar, and linker modifications that have been utilized to deliver nucleic acids (modified chemistry highlighted in blue)

affecting efficacy of the nanoparticle. As such, one laboratory has pioneered the use of semi-automated high-throughput synthesis methods to create libraries of chemically diverse lipids and lipid-like materials for RNA delivery [31-35], resulting in highly potent nanoparticles capable of delivering a variety of RNA types to both the liver [32, 36, 37] and the lung [33] following systemic delivery in vivo.

As an alternative to nanoparticles, a more conceptually straightforward and chemically well-defined means of delivery is to directly conjugate a bioactive ligand to the RNA that will allow it to enter the cell of interest. Perhaps the most clinically advanced example of this technique is the conjugation of $\mathrm{N}$-acetylgalactosamine (GalNAc; Fig. 1c), which targets the asialoglycoprotein receptor on hepatocytes, to siRNA [38]. Unlike many nanoparticles, which are given intravenously, GalNAc conjugates are typically dosed subcutaneously and have shown an ability to rapidly enter systemic circulation and target the liver [39]. Other conjugates, such as cholesterol [40], vitamin E [41], antibodies [42], and cell-penetrating peptides [43], have been explored in the past, although none but the specialized triantennary GalNAc-siRNA conjugate has gained any clinical traction (Table 2), suggesting the need for additional work on the design of conjugates for efficient delivery of nucleic acids. 


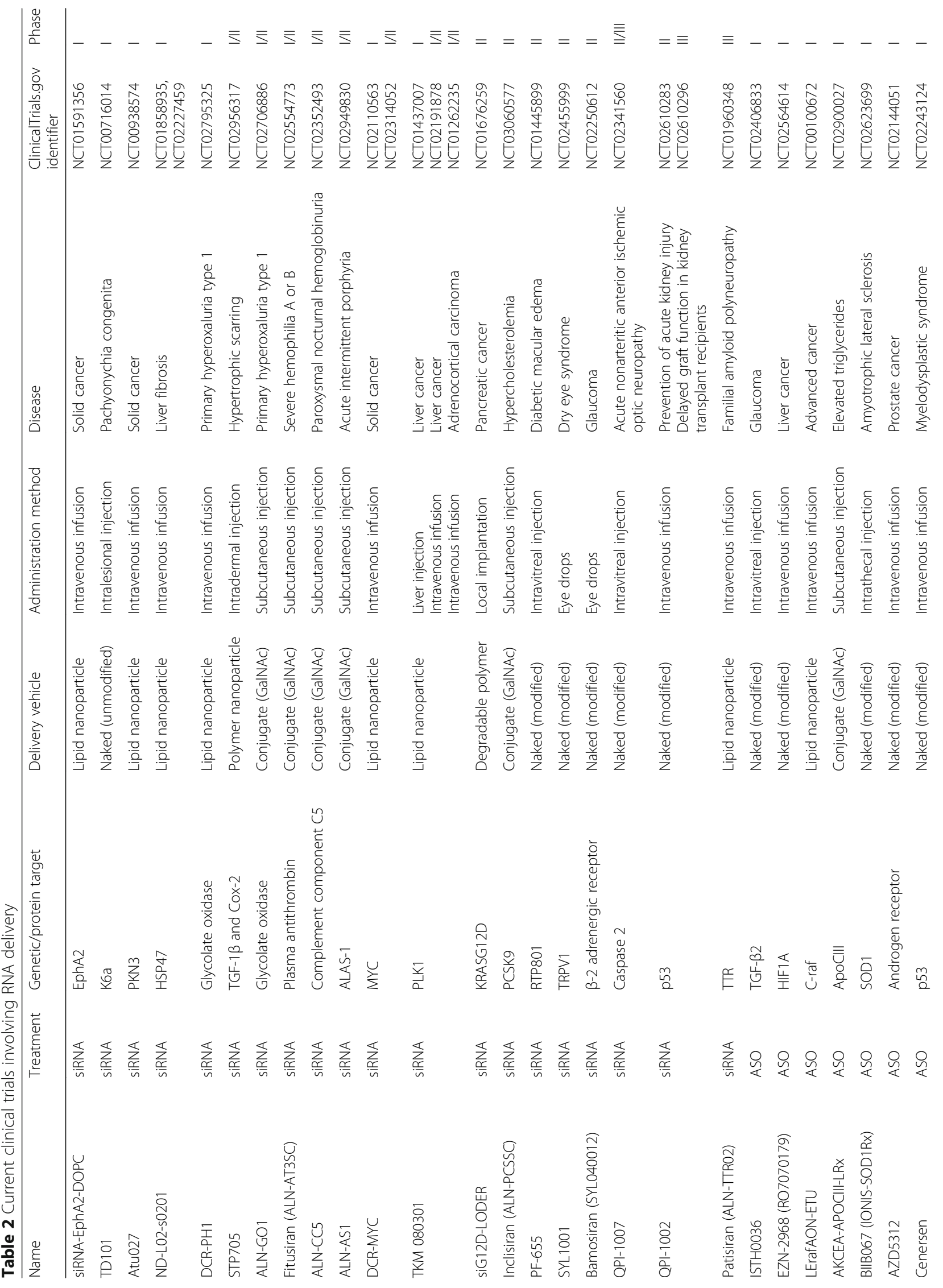




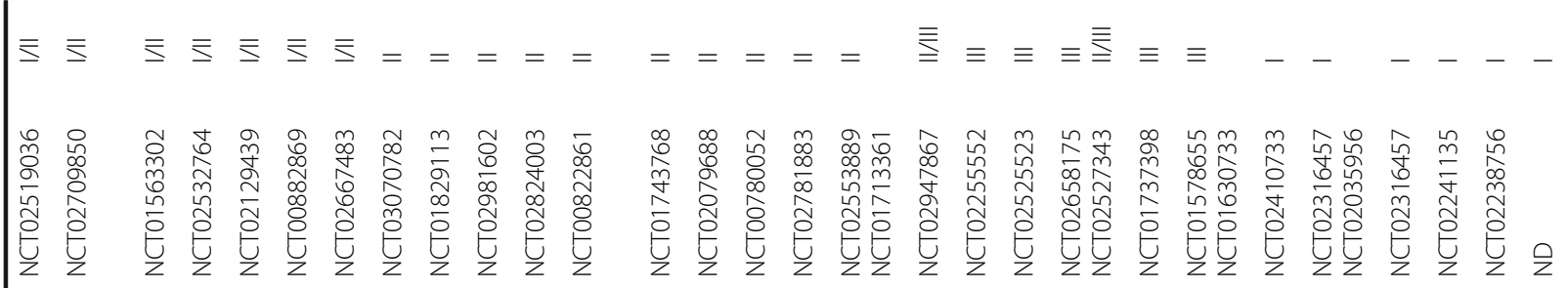

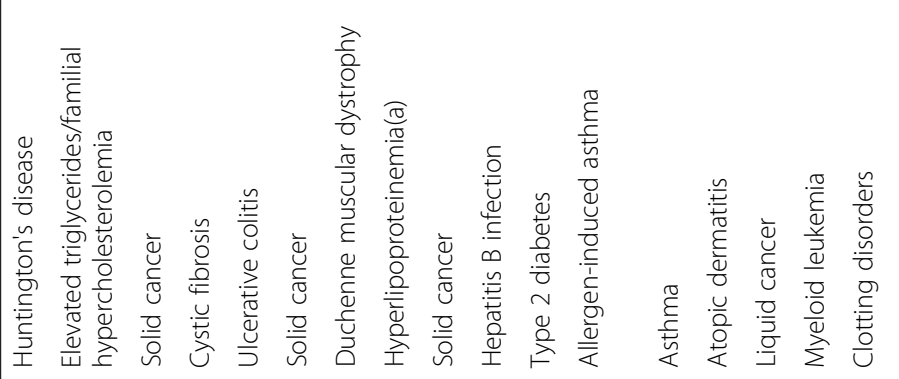

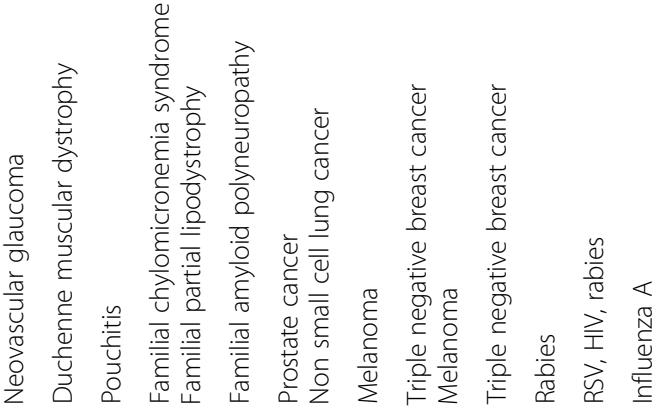

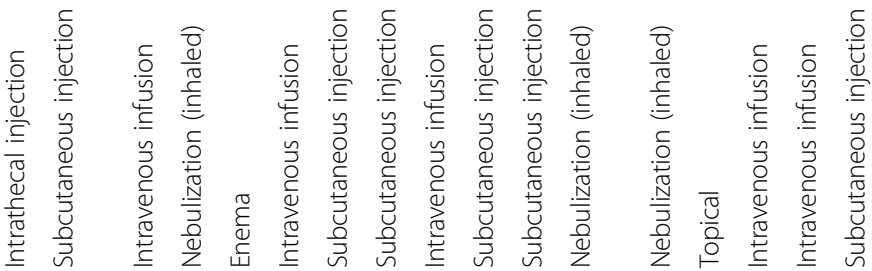

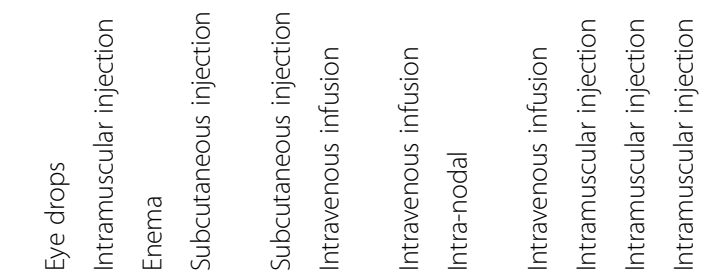

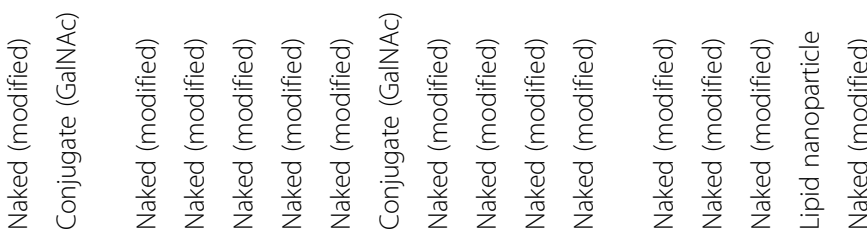

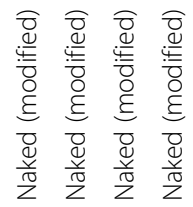

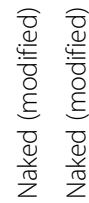

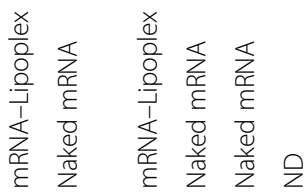

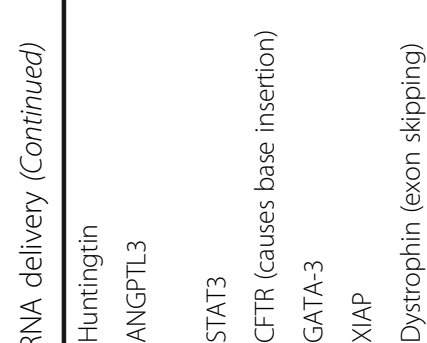

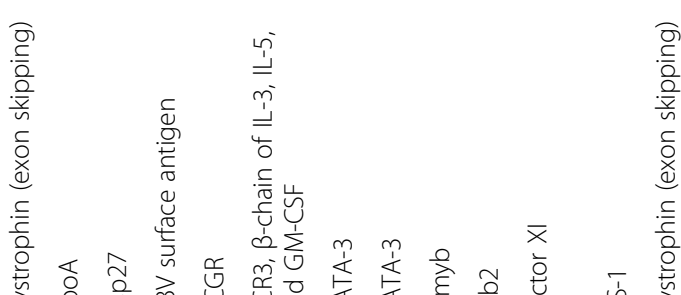

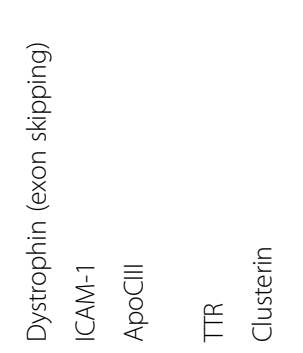

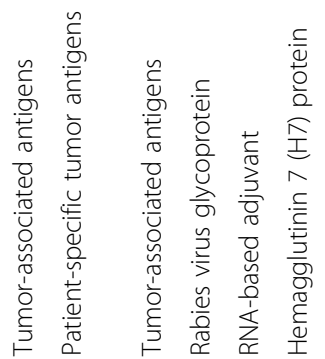

$\frac{\stackrel{2}{\frac{1}{2}}}{\frac{1}{2}}$

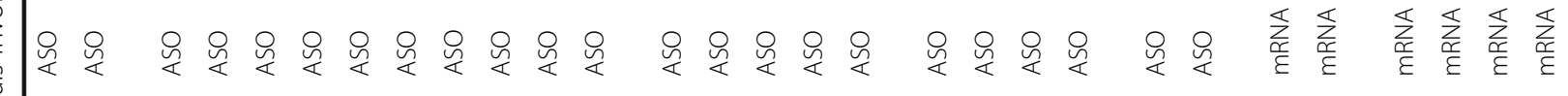

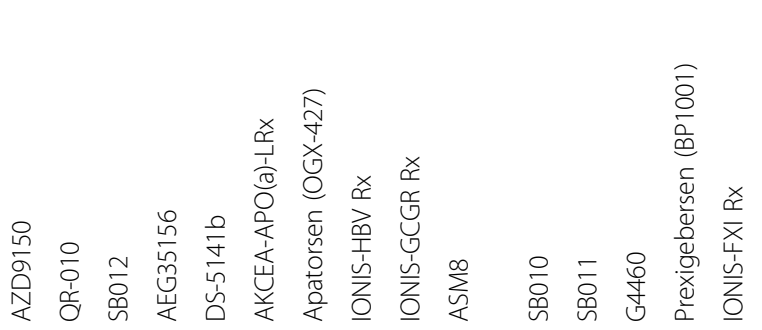

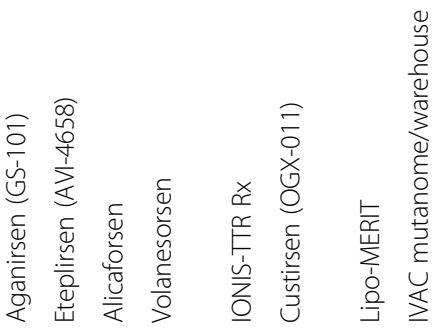

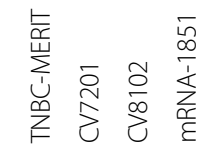




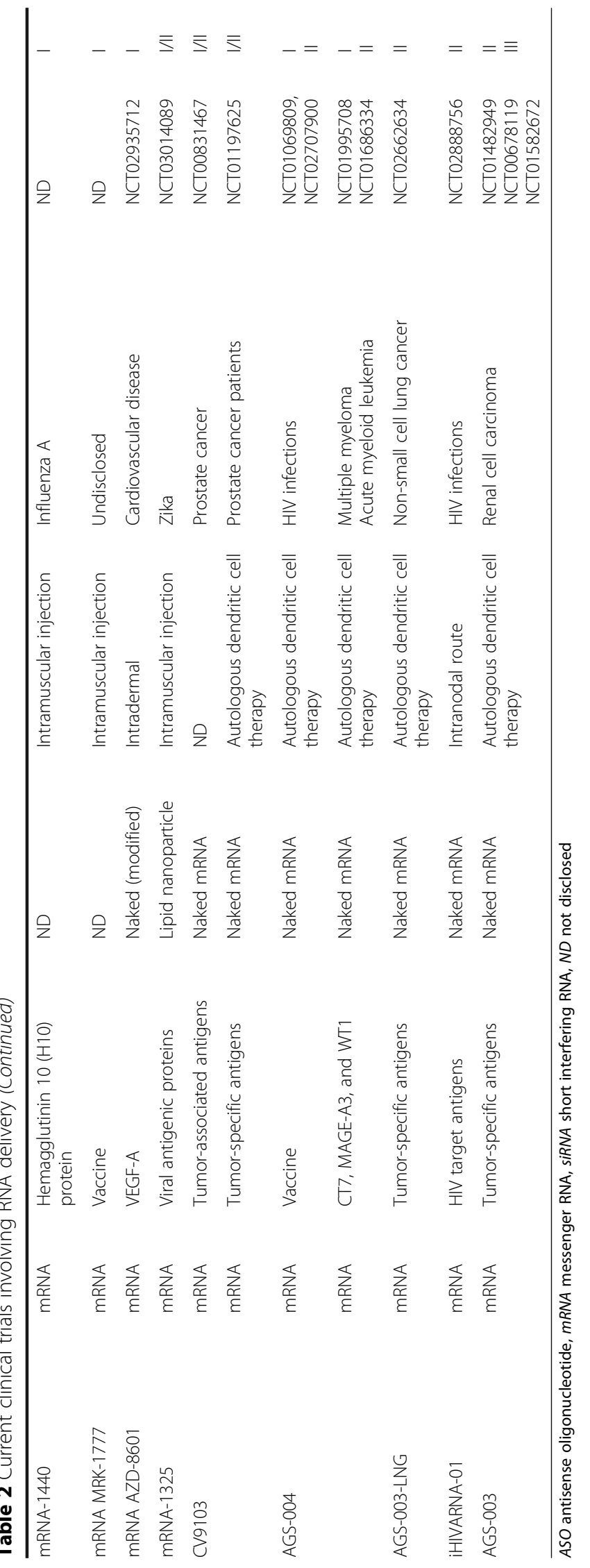




\section{RNA modifications}

Equally important for effective nucleic acid delivery are chemical modifications made to the RNA itself, which can impart degradation resistance to the RNA [44] and render them unrecognizable by the immune system [45]. This is true of both conjugate delivery systems, which leave the RNA exposed immediately upon injection, as well as nanoparticulate delivery systems, which must at some point expose the RNA to intracellular immune receptors. RNAs can be modified by means of chemical alterations to the ribose sugar (of particular importance is the $2^{\prime}$ position $\left.[45,46]\right)$, the phosphate linkage and the individual bases (Fig. 1d) [47-50]. RNAs delivered through nanoparticles, discussed later, are also typically modified in order to avoid recognition by endosomally expressed pattern recognition receptors [51]. With few exceptions, modified RNAs are the gold standard in clinical trials (Table 2). The degree to which the RNA can be modified and still retain its potency depends, to a large extent, on the nature of the nucleic acid and its mechanism of action. For instance, short RNAs such as siRNAs, which rely on the relatively robust RNAinduced silencing complex (RISC) [52], can typically be heavily modified. By contrast, large mRNAs, which must be effectively translated by ribosomes, are more sensitive to modifications and utilize naturally occurring RNA modification such as pseudouridine and 5-methylcytidine substitution [53]. Indeed, recent studies have shown that base modification of mRNA can actually decrease potency in certain situations [54], whereas chemical modification in siRNAs is almost ubiquitously applied for in vivo use [55].

\section{Applications of RNA-based gene/protein modulation}

\section{Protein downregulation-siRNA, ASOs, and microRNA}

In simplistic terms, disease-relevant proteins can be altered in one of two ways: upregulated or downregulated. The use of RNAs to selectively downregulate proteins experienced a paradigm shift following the discovery of siRNA by Fire and colleagues [56]. Short interfering RNAs are typically 21-23 base-pairs in length and can selectively bind and degrade complementary mRNA through the RISC (Fig. 2) [57]. After almost two decades of research, siRNA-based therapies represent one of the more clinically advanced platforms for RNA drugs. Alnylam Pharmaceuticals, in particular, has several siRNA drugs in clinical trials. Their most advanced drug, also one of the most advanced siRNA therapeutics, patisiran, is a LNP containing siRNA against mutant transthyretin for the treatment of transthyretin amyloidosis [58]. Patisiran is currently in phase III of clinical trials [59], having shown significant dose-dependent knockdown, with minimal adverse events, in phase II trials [60], and other companies have also invested in the use of lipoplex-based siRNA drugs (Table 2). Increasingly, however, Alnylam and others have reported significant progress with the GalNAc conjugate technology (Table 2). Despite Alnylam's recent decision to discontinue development of revusiran, a GalNAc-siRNA conjugate drug that also treats transthyretin amyloidosis [61], the company has several more GalNAc conjugates in its pipeline that utilize a newer 'enhanced stabilization chemistry' [62] that could address the issues that led to the removal of revusiran from clinical trials [61]. Surprisingly, some of the current clinical trials utilize naked, albeit chemically modified, siRNAs. Almost all of these naked siRNAs are delivered locally (Table 2), reducing the risk of RNA degradation and systemic immune activation compared with that associated with systemic delivery. An intriguing use of naked siRNA is Silenseed's siG12D LODER, which encapsulates siRNA targeted against the KRAS oncoprotein in an implantable and degradable polymeric matrix for the treatment of pancreatic cancer [63, 64]. However, there is concern that the positive effects of such treatments might in some cases be mediated by the induction of non-specific and immunological mechanisms such as siRNA binding to toll-like receptors [65].

Despite its significant presence in clinical trials, siRNA is not the only, or even the first, RNA drug to be investigated for protein knockdown at the clinical stage. The first RNA drugs widely used in clinical trials were antisense oligonucleotides (ASOs). Like siRNA, ASOs are designed to block protein translation through WatsonCrick base-pairing with the target mRNA [66] and can be modified to improve stability [67]. The ASOs, however, inhibit protein production through a variety of mechanisms, such as sterically blocking ribosome attachment or eliciting RNase-H activation [68]. They can also promote exon skipping (a form of RNA splicing which leaves out faulty exons), which allows for the deletion of faulty sequences within proteins [69], and, in some cases, can even lead to protein upregulation, which could be used therapeutically in diseases where certain genes are repressed [70]. An additional utility of ASOs is their ability to enter cells without the use of a transfection reagent, although this uptake does not always lead to therapeutic action [71]. Four ASOs have been clinically approved, all of which are chemically modified and used without a delivery vehicle, representing the only RNA drugs for protein modulation to be cleared by the FDA so far. The most recent, Spinraza (nusinersen), is injected intrathecally to treat spinal muscular atrophy [72]. It joined Exondys 51 (eteplirsen), an intravenously infused ASO for treatment of Duchenne muscular dystrophy [73], Vitravene (fomivirsen), an intravitreally injected ASO indicated for the treatment of ocular cytomegalovirus [74], and Kynamro (mipomersen), which is 


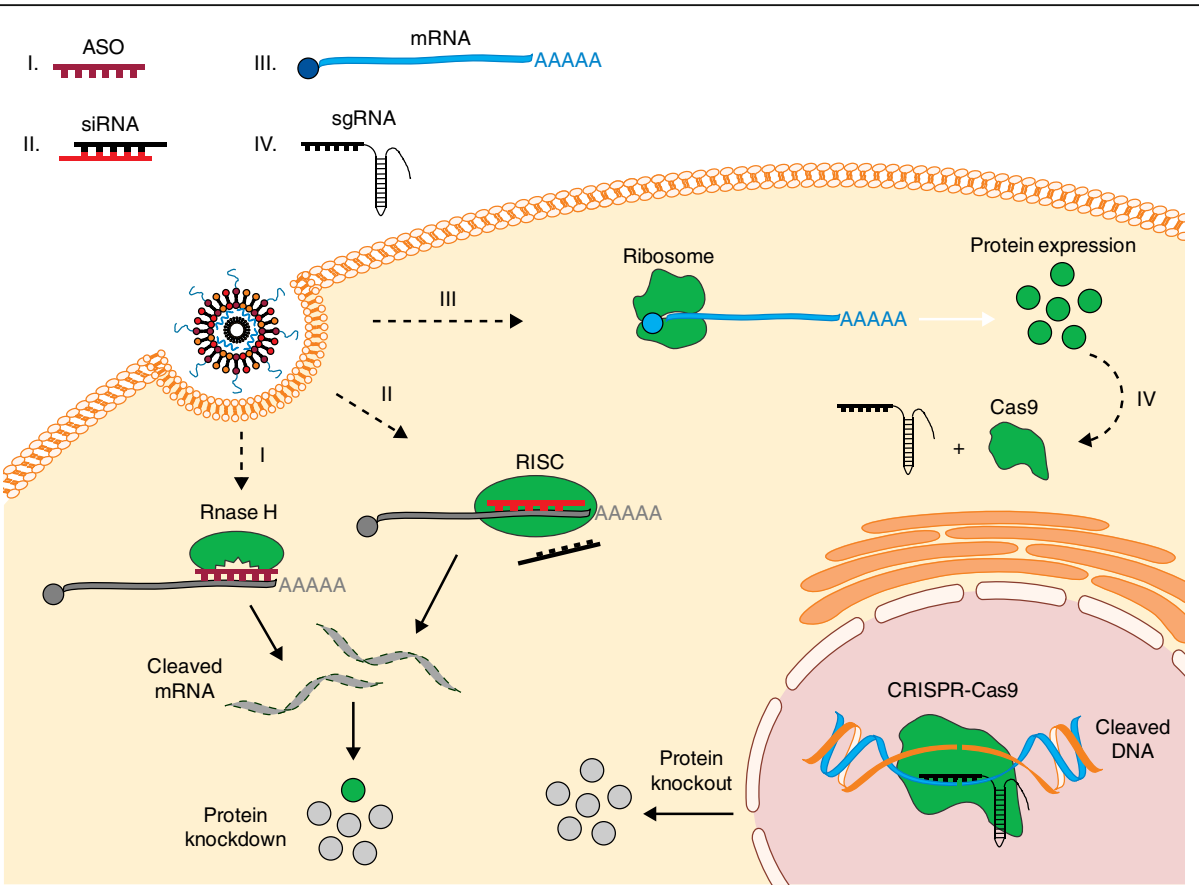

Fig. 2 Regulation of gene and protein expression using RNA. Once delivered into the cells, RNA macromolecules can utilize diverse intracellular mechanisms to control gene and protein expression. (I) Hybridization of antisense oligonucleotides (ASOs) to a target mRNA can result in specific inhibition of gene expression by induction of RNase $\mathrm{H}$ endonuclease activity, which cleaves the mRNA-ASO heteroduplex. (II) Short interfering RNA (siRNA) is recognized by the RNA-induced silencing complex (RISC), which, guided by an antisense strand of the siRNA, specifically binds and cleaves target mRNA. (III) In vitro transcribed mRNA utilizes the protein synthesis machinery of host cells to translate the encoded genetic information into a protein. Ribosome subunits are recruited to mRNA together with a cap and poly(A)-binding proteins, forming a translation initiation complex. (IV) In the CRISPR-Cas9 system, co-delivery of a single guide RNA (sgRNA) together with the mRNA encoding the Cas9 DNA endonuclease allows site-specific cleavage of double-stranded DNA, leading to the knockout of a target gene and its product. CRISPR, clustered regularly interspaced short palindromic repeats

injected subcutaneously and targets mRNA encoding apolipoprotein B for the treatment of hypercholesterolemia [75, 76]. There are still several ASOs in clinical trials, the majority of which are delivered without a vehicle (Table 2). Of particular interest are studies by Ionis Pharmaceuticals utilizing a GalNAc-ASO conjugate similar to that developed by Alnylam to deliver siRNA. Optimism from such approvals and clinical studies has also led researchers to continue investigation of ASOs to treat diseases such as amyotrophic lateral sclerosis (ALS) [77] and spinocerebellar ataxia [78].

An emerging, albeit less clinically advanced, RNAbased platform for protein knockdown is microRNA (miRNA). Endogenous microRNAs are non-coding RNAs that act as key regulators for a variety of cellular pathways, and are often downregulated in diseases [79]. Thus, exogenous microRNAs, or microRNA mimics, delivered therapeutically could be used to knockdown several proteins simultaneously, which is particularly useful in diseases such as cancer where having a single disease-relevant target is rare [80]. It is also worth noting that a rare subset of microRNAs is thought to enhance protein production, and that targeting of gene- suppressing microRNAs using ASOs could also be used to increase protein production [81]. The majority of current clinical trials involving microRNA are screens to investigate microRNA involvement in certain diseases, although there are several ongoing animal studies utilizing microRNA delivery. Examples include the use of LNPs to treat a mouse model of colorectal cancer [82], and polymeric nanoparticles to deliver microRNA to the heart to treat fibrosis [83]. The first microRNA mimic therapy to enter clinical trials was MRX-34-a liposomal-encapsulated microRNA mimic from Mirna Therapeutics meant to treat a variety of cancers [84]. However, the company terminated the study earlier in 2017 after reports of several immune-related severe adverse events [85]. The fact that the adverse events were immunological in character further highlights the importance of RNA modification for clinical applications, as such modifications remain one of the most important means of evading immune detection for RNA drugs. Chemical modification of miRNA mimics in particular, however, might prove challenging owing to the complex nature of miRNA-induced gene regulation [86]. 


\section{Protein overexpression-mRNA}

Expression of disease-relevant proteins can be achieved by intracellular delivery of plasmid DNA (pDNA) or messenger RNA (mRNA). Application of DNA or mRNA as protein intermediate enables expression of virtually any desired protein inside the host cells and tissues. This approach can address formulation and delivery challenges encountered with protein-based drugs, especially those aimed at intracellular targets [87]. mRNA-based therapeutics in particular offer several advantages over pDNA, including rapid and transient protein production, no risk of insertional mutagenesis, and greater efficacy of non-viral delivery by virtue of mRNA cytoplasmic activity (Fig. 2) [88]. Since the first pre-clinical studies in the 1990s, mRNA technology has greatly developed and now holds the potential to revolutionize vaccination, protein-replacement therapies, and treatment of genetic diseases, consequently gaining a considerable level of interest among the scientific community and biotech industry [53].

The delivery of mRNA therapeutics has been facilitated by significant progress in maximizing the translation and stability of mRNA, preventing its immune-stimulatory activity and the development of in vivo delivery technologies, some of which are discussed below. The 5' cap and $3^{\prime}$ poly(A) tail are the main contributors to efficient translation and prolonged half-life of mature eukaryotic mRNAs. Incorporation of cap analogs such as ARCA (anti-reverse cap analogs) and poly(A) tail of 120-150 bp into in vitro transcribed (IVT) mRNAs has markedly improved expression of the encoded proteins and mRNA stability $[89,90]$. New types of cap analogs, such as 1,2-dithiodiphosphate-modified caps, with resistance against RNA decapping complex, can further improve the efficiency of RNA translation [91]. Replacing rare codons within mRNA protein-coding sequences with synonymous frequently occurring codons, so-called codon optimization, also facilitates better efficacy of protein synthesis and limits mRNA destabilization by rare codons, thus preventing accelerated degradation of the transcript [92, 93]. Similarly, engineering $3^{\prime}$ and $5^{\prime}$ untranslated regions (UTRs), which contain sequences responsible for recruiting RNA-binding proteins (RBPs) and miRNAs, can enhance the level of protein product [53, 94]. Interestingly, UTRs can be deliberately modified to encode regulatory elements (e.g., K-turn motifs and miRNA binding sites), providing a means to control RNA expression in a cell-specific manner [95]. Some of the previously discussed RNA base modifications such as N1-methyl-pseudouridine have not only been instrumental in masking mRNA immune-stimulatory activity but have also been shown to increase mRNA translation by enhancing translation initiation [96, 97]. In addition to their observed effects on protein translation, base modifications and codon optimization affect the secondary structure of mRNA, which in turn influences its translation [98]. Understanding the importance of, and the ability to predict, the folding structure of mRNA could aid engineering of mRNA therapeutics-however, the accuracy of available prediction tools is currently limited. Despite the plethora of carriers studied for other types of RNA drugs, mRNA molecules are significantly larger (600$10,000 \mathrm{kDa})$ than the previously discussed siRNAs $(\sim 14 \mathrm{kDa})$ and ASOs $(4-10 \mathrm{kDa})$, which poses an additional challenge for delivery of mRNA therapeutics [99]. Accommodation of large and charged mRNAs into nanoparticles and their effective intracellular release has been shown to require fine-tuning of existing formulations and the development of a new-generation of biomaterials with higher potency [36, 37].

Therapeutic applications of mRNA that are currently being explored are vaccinations against cancer and infectious disease, protein-replacement therapy, and gene editing. A comprehensive list of ongoing clinical trials involving mRNA can be found in Table 2. mRNA vaccines are in the most-advanced stages of clinical development, following in the footsteps of competing DNA and protein-based technologies. Synthetic mRNA vaccines allow simultaneous delivery of a wide variety of antigens and are both faster and easier to manufacture at low cost in comparison with other systems, enabling a more-rapid response towards emerging pathogens [100]. Additionally, immune responses generated by naked mRNA can be beneficial for vaccination purposes [101, 102]. Immunization against infectious diseases using ex vivo mRNA-transfected dendritic cells (DCs) is now being pursued in clinical trials and has demonstrated good safety profiles and ability to induce antigen-specific T-cell responses [103].

Another RNA vaccination approach is the use of selfamplifying mRNA replicons that have been developed to extend the duration and magnitude of antigen expression as well as boost the immune response $[104,105]$. In a recent study, replicon vaccines formulated into nanoparticles comprising repeatedly branched dendrimer (tree-like) molecules have generated protective immunity against a broad spectrum of lethal pathogens, including Zika, Ebola and influenza viruses [106]. Conventional, modified mRNAs are also being explored for vaccination [105]. Lipid-nanoparticle-encapsulated mRNAs encoding pre-membrane and envelope glycoproteins of Zika virus have recently been reported to elicit potent and durable neutralizing antibody responses in mice and non-human primates against the virus after intradermal administration [107]. Moreover, expression of modified mRNA encoding broadly neutralizing antibody in the liver, after systemic administration of mRNA-LNPs, has protected 
humanized mice against HIV-1 challenge [108]. Cancer mRNA vaccines have experienced accelerated development and clinical translation driven by the success of cancer immunotherapy. The majority of approaches tested in clinical trials employ adoptive-transfer of DCs transfected with mRNAs coding for tumor-specific antigens (TSAs) and immunomodulation of $\mathrm{T}$ cells with mRNAs expressing chimeric antigen receptors (CARs) or TSAs [109]. In addition, direct intradermal and systemic administration of LNP-formulated mRNAs coding for tumor-specific antigens is currently being investigated in the clinic for induction of $\mathrm{T}$-cell immune responses $[100,110,111]$.

By contrast, most mRNA-based protein replacement therapies are still in the preclinical stages of development and involve supplementation of deficient or aberrant proteins as well as modulation of cell behavior by expression of exogenous proteins. The in vivo efficacy of RNA-protein therapy has been demonstrated for a number of diseases. The majority of the studies preferentially target the liver owing to the well-established and efficient methods for RNA delivery into liver tissue. Therapeutically relevant amounts of human FIX (hFIX) protein were reached and sustained physiological activity for 4-9 days upon a single intravenous dose of hFIX mRNA-loaded LNPs in mice with hemophilia B $[112,113]$. Similarly, LNPs formulated with mRNA encoding erythropoietin (Epo) have been shown to elicit a systemic physiological response in large animals, including pigs and nonhuman primates [93]. Therapeutic effects of mRNA have also been demonstrated in other tissues. Lung delivery of surfactant protein B (SP-B) mRNA protected mice from respiratory failure [114], whereas myocardial injection of RNAiMAX-formulated mRNA, encoding human vascular endothelial growth factor A (VEGF-A), improved heart regeneration after myocardial infarction in mice [115]. Based on this notion, Astra Zeneca partnered by Moderna has launched a phase I clinical trial for local delivery of VEGF mRNA, starting January 2017 [116]. Pre-clinical studies have demonstrated the translational potential of mRNA-based protein therapy for both secreted and intracellular protein targets. However, treatment of chronic diseases might carry an elevated risk of toxicity, associated with the repeated mRNA-LNP administrations required to sustain therapeutic levels of protein. Using mRNA for delivery of gene editing tools could address this challenge and is discussed below.

\section{Gene editing}

The RNA-based technologies discussed above constitute a powerful means to transiently repress or overexpress the expression of genes. By contrast, therapeutic gene editing entails replacement or alteration of gene expression by introducing site-specific modifications into the genome of cells, including correction of deleterious or introduction of protective mutations [117]. While the majority of current gene editing efforts are focused on treatment of monogenic disorders, caused by deleterious changes in a single gene, the expansion of gene editing and delivery tools makes the treatment of complex polygenic diseases such as cardiovascular diseases [118] and antiviral therapies [119], as well as editing the epigenome, more feasible [120]. The discovery of RNAguided DNA endonucleases such as Cas9 associated with CRISPR (clustered regularly interspaced short palindromic repeats), elements composing the prokaryotic adaptive immune system [121], equipped scientists with an easy-to-use and efficient platform to alter genomic information [122]. So-called CRISPR-Cas systems rely on Watson-Crick base-pairing between a single guide RNA (sgRNA) and a corresponding DNA target site followed by a distinct protospacer-adjacent motif (PAM), a 3-5-nucleotide DNA sequence required for binding of Cas9 and cleavage of the target sequence, in order to introduce a double-stranded break (DSB) into a DNA molecule [123]. DSBs can be repaired by the cells using non-homologous end joining (NHEJ) and homology-directed repair (HDR). NHEJ results in stochastic insertions and deletions ('indels') causing permanent gene knockout, whereas HDR occurs in the presence of a DNA template containing homology to regions flanking the DSB site, leading to incorporation of desired changes encoded in the repair template into the genome [124]. A combination of DSBs can also be used to edit multiple loci by employing different sgRNAs $[125,126]$.

To date, the most widely used and well characterized gene-editing technology is the CRISPR-Cas9 system with an effector domain originating from Streptococcus pyogenes (SpCas9). Direct in vivo delivery of spCas9 to diseased cells has recently been used to correct mutations in genes in animal models of Duchenne muscular dystrophy $(m d x)$ [127-129], hereditary tyrosynemia type I $(f a h)[130,131]$, and lethal metabolic liver disease (oct) [132] and to reduce blood cholesterol in chimeric mice with humanized liver by knockout of PCSK9 [133]. Ex vivo editing with spCas9 has been applied to human hematopoietic stem cells in order to correct sickle cell anemia caused by mutation in the gene encoding $\beta$ globin, as well as to deplete $\mathrm{T}$ cells of expression of CCR5 to trigger anti-HIV protection or to deplete PD-1 to boost anti-cancer therapy [134]. Despite positive outcomes, these studies have revealed limitations of the CRISPR-Cas9 system relevant for clinical translation, including (1) imperfect DNA-targeting specificity leading to off-target effects [135], (2) low efficiency of genome editing using HDR [136], and (3) challenging delivery of 
CRISPR-Cas9 components using both viral and nonviral methods [137].

The DNA-targeting specificity of CRISPR-Cas9 can be improved by combining optimized design and synthesis of guide RNAs. In particular, sgRNAs shorter than 20 nucleotides and containing $5^{\prime}$ mismatches have shown fewer off-target effects [138, 139], whereas chemically synthesized sgRNAs bearing base modifications at the $5^{\prime}$ and $3^{\prime}$ ends have demonstrated increased on-target efficacy [140]. Furthermore, improved types of spCas9, such as high-fidelity spCas9-HF1 [141] or enhanced-specificity eSpCas9 [142], have been engineered by introducing specific mutations into spCas9 based on interactions between a spCas9-gRNA complex and DNA. New RNAguided nucleases, such as Cpf1 from Acidaminococcus sp. (AsCpf1), with the capability to edit the genome of mammalian cells have been discovered recently [143, 144]. Cpf1 nuclease mRNA $(\sim 1.3 \mathrm{~kb})$ is significantly smaller than Cas9, with a different PAM requirement and inherently higher DNA specificity than spCas9, which makes it attractive for clinical use. Off-target effects can be also limited by decreasing the cellular presence of spCas9 through conditions favoring transient over long-lasting expression, which can be accomplished by optimizing the delivery method $[140,145]$.

Obtaining a better efficiency of genome editing by HDR will be necessary to address genetic diseases demanding a high level of therapeutic product, especially when edited cells do not display a positive change in fitness and outcompete their diseased counterparts over time [117]. The efficiency of correction by HDR can be significantly improved by designing an asymmetric single-stranded DNA template that anneals to the non-target DNA strand, which is the first to be released from the Cas9-DNA complex [146]. In addition, a number of studies have reported better HDR efficacy by using CRISPR-Cas9 in combination with small-molecule inhibitors of NHEJ, such as DNA ligase IV or DNA-dependent protein kinase inhibitors [147, 148]. Alternatively, HDR can be enhanced by agonists of proteins crucially involved in homologous recombination such as Rad51 [149]. Recently, other methods of gene editing with CRISPR-Cas9, called homology-independent targeted integration (HITI), have been developed, which exploit the NHEJ repair mechanism for gene knock-ins [150]. HITI donor templates are designed to ensure robust gene integration only when inserted in the correct direction as otherwise the target DNA would undergo additional cleavage by Cas9. This method has demonstrated higher in vitro efficacy of transgene insertion in comparison with HDR-dependent editing, but so far when conducted in vivo it reached only $3-10 \%$ of the knock-in efficiencies.
Intracellular delivery of CRISPR-based agents poses one of the most significant challenges for therapeutic genome editing owing to the number of essential components. CRISPR-Cas9 components can be delivered as DNA, RNA, RNA-protein complex (RNP), or a combination of these macromolecules. These macromolecules are not able to spontaneously enter the cells, relying on the use of delivery vehicles such as viral vectors, nanoparticles, or physical and mechanical delivery methods like nucleofection, cell squeezing, or lipofection that utilize electric field, mechanical force, or cationic lipids for temporary disruption of the cell membrane [151]. The latter are primarily suited for therapeutic ex vivo gene editing, while viral vectors and nanoparticles are mainly used for in vivo gene therapy [152].

Viral delivery of CRISPR-Cas9 has been explored using lentivirus, adeno-virus, and adeno-associated virus (AAV) [137]. AAVs are most widely used for gene therapy clinical trials due to their ability to transduce different cell types and tissues and their low risk of genomic integration and low immunogenicity [153]. However, AAV-limited packaging capacity $(\sim 4.5 \mathrm{~kb})$ makes it impossible to accommodate all the components of CRISPR-spCas9, including sgRNA and a donor DNA template, into a single AAV. Noteworthy is that a host immune response to AAV-CRISPR-Cas9 has been observed in mice, elicited by Cas 9 immunogenicity and possibly aggravated by its prolonged expression [154].

Complementary to the viral systems, an abundance of nanoparticles comprising various bio-compatible materials are being developed for delivery of CRISPR-Cas9. As with their use in protein modulation, nanoparticles for gene editing have demonstrated high loading capacity for nucleic acid cargos, ability to modify payload bio-distribution and pharmacokinetics through active targeting and formulation, as well as simplicity of manufacturing with a high level of control over their physicochemical parameters, such as size/shape and kinetics of payload release [155]. Nanoparticle-based mRNA delivery of CRISPR-Cas components is therapeutically attractive owing to the transient nature of mRNA expression, no risk of genomic integration and mRNA cytoplasmic activity, alleviating the need to overcome the nuclear barrier in comparison with pDNA (Fig. 2). To date, nanoparticle-mediated delivery of spCas 9 mRNA has been used in combination with AAVs encoding a sgRNA and a repair template to induce repair of the Fah gene in a hereditary tyrosinemia in adult animals [131]. The efficiency of correction was $>6 \%$ of hepatocytes after a single application, much higher than with a hydrodynamic injection of pDNA (0.4\%) previously reported for the same disease [130]. Similarly, lung delivery of mRNA encoding zinc-finger nucleases complexed into chitosan-coated nanoparticles, used in combination 
with an AAV6-expressing donor template, resulted in correction of the gene encoding surfactant protein $\mathrm{B}$ in mice with SP-B deficiency and extended their survival [156]. Interestingly, the combination of mRNA nanoparticle with the virus was superior to AAV alone, reaching HDR rates in lung cells of $\sim 9 \%$. Recently, a study described the synthesis and development of zwitterionic amino lipids, composed of a sulfobetaine head group and a polyamine linker with hydrophobic tails, that were used to formulate nanoparticles capable of simultaneous in vivo delivery of Cas9 mRNA and sgLoxP to induce expression of floxed tdTomato in the liver, kidneys, and lungs of LSL-TdTomato mice [157]. This study shows the potential of the nanoparticle-RNA platform to accommodate multiple components of CRISPR-Cas9 into a single carrier, and could possibly be extended to also include a donor template. Lipid and polypeptide nanoparticles have also been used to deliver RNA-protein complex of Cas9 and sgRNAs, which is another promising strategy to ensure the transient cellular presence of Cas9, significantly reducing off-target effects $[158,159]$. However, the therapeutic potential of in vivo RNP delivery has yet to be demonstrated.

\section{Conclusions}

After over two decades of development, RNA therapeutics has become a clinical reality. The design and chemistries used to synthesize siRNAs, ASOs, and mRNAs have advanced to a point where they enable adequate stability and immune evasion, while at the same time allowing the maintenance of efficacy and specificity. The delivery technologies have also greatly progressed thanks to the discovery of potent and bio-compatible materials, aided by high-throughput screening technologies. Despite recent setbacks surrounding withdrawal of Alnylams's siRNA-GalNac conjugate [160] and Curevac's first mRNA vaccine [100] from clinical trials, nucleic acid-based therapeutics continue to progress, as highlighted by the approval of four ASOs by the FDA [159] and more RNA candidate drugs with improved chemical modifications entering advanced stages of human trials (Table 2). In addition, the enormous excitement surrounding CRISPR-Cas genome editing and its transformational impact on biomedical sciences has spurred the development of RNA-based delivery approaches to facilitate clinical translation of CRISPR-Cas technology. The first US-based human trial conducted by the University of Pennsylvania will use CRISPR-Cas9 ex vivo to knock out the genes encoding PD1 and T-cell receptor alpha/beta in $\mathrm{T}$ cells isolated from cancer patients for cancer therapy [161]. The leading CRISPR biotech companies such as CRISPR Therapeutics [162], Editas Medicine [163], and Intellia Therapeutics [164] have programs in advanced pre-clinical stages of development in their portfolios and will likely soon follow the clinical route. These companies mostly focus on disorders affecting liver, lung, and hematopoiesis, while developing both ex vivo and in vivo delivery approaches utilizing AAVs, LNPs, and RNPs [162-164]. This highlights that safety and delivery remain the major challenges for RNA-based drugs, especially for RNA-protein and CRISPR-Cas therapies, and will be shaping the scope of upcoming clinical trials. Undoubtedly, the field of RNA therapeutics is currently undergoing a major expansion, and the potential for using RNA drugs for personalized medicine and immunotherapy as well as to address genetic, infectious, and chronic diseases will ensure the continued development of RNA therapeutics for years to come.

\begin{abstract}
Abbreviations
AAV: Adeno-associated virus; ARCA: Anti-reverse-cap analog; AsCpf1: Cpf1 nuclease derived from Acidaminococcus species; ASO: Antisense oligonucleotide; CAR: Chimeric antigen receptor; CRISPR: Clustered regularly interspaced short palindromic repeats; DC: Dendritic cell; DSB: Double-strand break; EPO: Erythropoietin; HDR: Homology-directed repair; hFIX: Human factor IX; HITI: Homology-independent targeted integration; LNP: Lipid nanoparticle; miRNA: MicroRNA; NHEJ: Nonhomologous end joining; PAM: Protospacer-adjacent motif; RBP: RNA-binding protein; RISC: RNA-induced silencing complex; RNP: RNA-protein complex; sgRNA: Short guide RNA; siRNA: Short interfering RNA; SP-B: Surfactant protein B; spCas9: Cas9 nuclease derived from Streptococcus pyogenes; TSA: Tumor-specific antigen; UTR: Untranslated region; VEGF-A: Vascular endothelial growth factor A
\end{abstract}

\section{Funding}

PSK acknowledges funding from the Juvenile Diabetes Research Foundation (JDRF) postdoctoral fellowship Grant 3-PDF-2017-383-A-N. The authors acknowledge funding from the Cancer Center Support (core) Grant P30-CA14051 from the $\mathrm{NCl}$.

\section{Authors' contributions}

JCK, PSK, and DGA conceived and co-wrote the manuscript. JCK and PSK provided equal contributions in manuscript preparation. All authors read and approved the final manuscript.

\section{Competing interests}

The authors declare that they have no competing interests.

\section{Publisher's Note}

Springer Nature remains neutral with regard to jurisdictional claims in published maps and institutional affiliations.

\section{Author details}

${ }^{1}$ Department of Chemical Engineering, Massachusetts Institute of Technology, Cambridge, Massachusetts 02139, USA. ²David H. Koch Institute for Integrative Cancer Research, Massachusetts Institute of Technology, Cambridge, Massachusetts 02139, USA. Institute for Medical Engineering and Science, Massachusetts Institute of Technology, Cambridge,

Massachusetts 02139, USA. ${ }^{4}$ Harvard and MIT Division of Health Science and Technology, Massachusetts Institute of Technology, Cambridge,

Massachusetts 02139, USA

Published online: 27 June 2017

\section{References}

1. Goodwin S, McPherson JD, McCombie WR. Coming of age: ten years of next-generation sequencing technologies. Nat Rev Genet. 2016;17:333-51.

2. Stratton MR. Exploring the genomes of cancer cells: progress and promise. Science. 2011;331:1553-8. 
3. Lin MK, Farrer MJ. Genetics and genomics of Parkinson's disease. Genome Med. 2014;6:48.

4. Jarvis JN, Frank MB. Functional genomics and rheumatoid arthritis: where have we been and where should we go? Genome Med. 2010;2:44.

5. Bertram L, Tanzi RE. Thirty years of Alzheimer's disease genetics: the implications of systematic meta-analyses. Nat Rev Neurosci. 2008;9:768-78.

6. Auffray C, Chen Z, Hood L. Systems medicine: the future of medical genomics and healthcare. Genome Med. 2009:1:2.

7. Verdine GL, Walensky LD. The challenge of drugging undruggable targets in cancer: lessons learned from targeting BCL-2 family members. Clin Cancer Res. 2007;13:7264-70.

8. Hopkins AL, Groom CR. The druggable genome. Nat Rev Drug Discov. 2002; 1:727-30.

9. Wolff JA, Malone RW, Williams P, Chong W, Acsadi G, Jani A, et al. Direct gene transfer into mouse muscle in vivo. Science. 1990;247:1465-8.

10. Sahay G, Alakhova DY, Kabanov AV. Endocytosis of nanomedicines. J Control Release. 2010;145:182-95.

11. Kotterman MA, Schaffer DV. Engineering adeno-associated viruses for clinical gene therapy. Nat Rev Genet. 2014;15:445-51.

12. Anderson DG, Lynn DM, Langer R. Semi-automated synthesis and screening of a large library of degradable cationic polymers for gene delivery. Angew Chemie Int Ed. 2003:42:3153-8.

13. Pack DW, Hoffman AS, Pun S, Stayton PS. Design and development of polymers for gene delivery. Nat Rev Drug Discov. 2005;4:581-93.

14. Behr J. The proton sponge: a trick to enter cells the viruses did not exploit. Int J Chem. 1997;2:34-6.

15. Rehman ZU, Hoekstra D, Zuhorn IS. Mechanism of polyplex- and lipoplexmediated delivery of nucleic acids: real-time visualization of transient membrane destabilization without endosomal lysis. ACS Nano. 2013;7: 3767-77.

16. Won $Y-Y$, Sharma R, Konieczny SF. Missing pieces in understanding the intracellular trafficking of polycation/DNA complexes. J Control Release. 2009;139:88-93.

17. Guo J, Cheng WP, Gu J, Ding C, Qu X, Yang Z, et al. Systemic delivery of therapeutic small interfering RNA using a $\mathrm{pH}$-triggered amphiphilic poly-Llysine nanocarrier to suppress prostate cancer growth in mice. Eur J Pharm Sci. 2012;45:521-32.

18. Tsutsumi T, Hirayama F, Uekama K, Arima H. Evaluation of polyamidoamine dendrimer/alpha-cyclodextrin conjugate (generation 3, G3) as a novel carrier for small interfering RNA (siRNA). J Control Release. 2007;119:349-59.

19. Boussif O, Lezoualc'h F, Zanta MA, Mergny MD, Scherman D, Demeneix B, et al. A versatile vector for gene and oligonucleotide transfer into cells in culture and in vivo: polyethylenimine. Proc Natl Acad Sci U S A. 1995;92: 7297-301.

20. Howard KA, Rahbek UL, Liu X, Damgaard CK, Glud SZ, Andersen M, et al. RNA interference in vitro and in vivo using a novel chitosan/siRNA nanoparticle system. Mol Ther. 2006;14:476-84

21. Lynn DM, Langer R. Degradable poly(ß-amino esters): synthesis, characterization, and self-assembly with plasmid DNA. J Am Chem Soc. 2000;122:10761-8.

22. Kozielski KL, Tzeng SY, Green JJ. A bioreducible linear poly( $($-amino ester) for siRNA delivery. Chem Commun (Camb). 2013;49:5319-21.

23. Tzeng SY, Hung BP, Grayson WL, Green JJ. Cystamine-terminated poly(beta-amino ester)s for siRNA delivery to human mesenchymal stem cells and enhancement of osteogenic differentiation. Biomaterials. 2012; 33:8142-51

24. Dosta P, Segovia N, Cascante A, Ramos V, Borrós S. Surface charge tunability as a powerful strategy to control electrostatic interaction for high efficiency silencing, using tailored oligopeptide-modified poly(beta-amino ester)s (PBAEs). Acta Biomater. 2015;20:82-93.

25. Kaczmarek JC, Patel AK, Kauffman KJ, Fenton OS, Webber MJ, Heartlein MW, et al. Polymer-lipid nanoparticles for systemic delivery of mRNA to the lungs. Angew Chemie Int Ed. 2016;55:13808-12.

26. Schroeder A, Levins CG, Cortez C, Langer R, Anderson DG. Lipid-based nanotherapeutics for siRNA delivery. J Intern Med. 2010;267:9-21.

27. Kanasty $R$, Dorkin JR, Vegas A, Anderson D. Delivery materials for siRNA therapeutics. Nat Mater. 2013;12:967-77.

28. Desigaux L, Sainlos M, Lambert O, Chevre R, Letrou-Bonneval E, Vigneron $J-P$, et al. Self-assembled lamellar complexes of siRNA with lipidic aminoglycoside derivatives promote efficient siRNA delivery and interference. Proc Natl Acad Sci U S A. 2007;104:16534-9.
29. Leus NGJ, Morselt HWM, Zwiers PJ, Kowalski PS, Ruiters MHJ, Molema G, et al. VCAM-1 specific PEGylated SAINT-based lipoplexes deliver siRNA to activated endothelium in vivo but do not attenuate target gene expression. Int J Pharm. 2014:469:121-31.

30. Chen D, Love KT, Chen Y, Eltoukhy AA, Kastrup C, Sahay G, et al. Rapid discovery of potent siRNA-containing lipid nanoparticles enabled by controlled microfluidic formulation. J Am Chem Soc. 2012;134:6948-51.

31. Love KT, Mahon KP, Levins CG, Whitehead KA, Querbes W, Dorkin JR, et al. Lipid-like materials for low-dose, in vivo gene silencing. Proc Natl Acad Sci U S A. 2010;107:1864-9.

32. Dong $Y$, Love KT, Dorkin JR, Sirirungruang S, Zhang $Y$, Chen D, et al. Lipopeptide nanoparticles for potent and selective siRNA delivery in rodents and nonhuman primates. Proc Natl Acad Sci U S A. 2014;111: 3955-60.

33. Dahlman JE, Barnes C, Khan OF, Thiriot A, Jhunjunwala S, Shaw TE, et al. In vivo endothelial siRNA delivery using polymeric nanoparticles with low molecular weight. Nat Nanotechnol. 2014;9:648-55.

34. Akinc A, Goldberg M, Qin J, Dorkin JR, Gamba-Vitalo C, Maier M, et al. Development of lipidoid-siRNA formulations for systemic delivery to the liver. Mol Ther. 2009;17:872-9.

35. Akinc A, Zumbuehl A, Goldberg M, Leshchiner ES, Busini V, Hossain N, et al. A combinatorial library of lipid-like materials for delivery of RNAi therapeutics. Nat Biotechnol. 2008;26:561-9.

36. Kauffman KJ, Dorkin JR, Yang JH, Heartlein MW, DeRosa F, Mir FF, et al. Optimization of lipid nanoparticle formulations for mRNA delivery in vivo with fractional factorial and definitive screening designs. Nano Lett. 2015;15: 7300-6.

37. Fenton OS, Kauffman KJ, McClellan RL, Appel EA, Dorkin JR, Tibbitt MW, et al. Bioinspired alkenyl amino alcohol ionizable lipid materials for highly potent in vivo mRNA delivery. Adv Mater. 2016;28:2939-43.

38. Nair JK, Willoughby JLS, Chan A, Charisse K, Alam MR, Wang Q, et al. Multivalent $\mathrm{N}$-acetylgalactosamine-conjugated siRNA localizes in hepatocytes and elicits robust RNAi-mediated gene silencing. J Am Chem Soc. 2014;136:16958-61.

39. Yu RZ, Graham MJ, Post N, Riney S, Zanardi T, Hall S, et al. Disposition and pharmacology of a GalNAc3-conjugated ASO targeting human lipoprotein(a) in mice. Mol Ther Nucleic Acids. 2016;5, e317.

40. Lorenz C, Hadwiger P, John M, Vornlocher HP, Unverzagt C. Steroid and lipid conjugates of siRNAs to enhance cellular uptake and gene silencing in liver cells. Bioorganic Med Chem Lett. 2004;14:4975-7.

41. Nishina K, Unno T, Uno Y, Kubodera T, Kanouchi T, Mizusawa H, et al. Efficient in vivo delivery of siRNA to the liver by conjugation of alphatocopherol. Mol Ther. 2008;16:734-40.

42. Xia C-F, Boado RJ, Pardridge WM. Antibody-mediated targeting of siRNA via the human insulin receptor using avidin - biotin technology. Mol Pharm. 2009;6:747-51.

43. Moschos SA, Jones SW, Perry MM, Williams AE, Erjefalt JS, Turner JJ, et al. Lung delivery studies using siRNA conjugated to TAT(48-60) and penetratin reveal peptide induced reduction in gene expression and induction of innate immunity. Bioconjug Chem. 2007;18:1450-9.

44. Soutschek J, Akinc A, Bramlage B, Charisse K, Constien R, Donoghue M, et al. Therapeutic silencing of an endogenous gene by systemic administration of modified siRNAs. Nature. 2004;432:173-8.

45. Morrissey DV, Lockridge JA, Shaw L, Blanchard K, Jensen K, Breen W, et al. Potent and persistent in vivo anti-HBV activity of chemically modified siRNAs. Nat Biotechnol. 2005;23:1002-7.

46. Wittrup A, Lieberman J. Knocking down disease: a progress report on siRNA therapeutics. Nat Rev Genet. 2015;16:543-52.

47. Bramsen JB, Laursen MB, Nielsen AF, Hansen TB, Bus C, Langkjoør N, et al. A large-scale chemical modification screen identifies design rules to generate siRNAs with high activity, high stability and low toxicity. Nucleic Acids Res. 2009;37:2867-81.

48. Chiu Y-L, Rana TM. siRNA function in RNAi: a chemical modification analysis. RNA. 2003:9:1034-48.

49. Prakash TP, Allerson CR, Dande P, Vickers TA, Sioufi N, Jarres R, et al. Positional effect of chemical modifications on short interference RNA activity in mammalian cells. J Med Chem. 2005;48:4247-53.

50. Li B, Luo X, Dong Y. Effects of chemically modified messenger RNA on protein expression. Bioconjug Chem. 2016;27:849-53.

51. Judge A, MacLachlan I. Overcoming the innate immune response to small interfering RNA. Hum Gene Ther. 2008;19:111-24. 
52. Pratt AJ, MacRae IJ. The RNA-induced silencing complex: a versatile genesilencing machine. J Biol Chem. 2009;284:17897-901.

53. Sahin U, Karikó K, Türeci Ö. mRNA-based therapeutics—developing a new class of drugs. Nat Rev Drug Discov. 2014;13:759-80.

54. Kauffman KJ, Mir FF, Jhunjhunwala S, Kaczmarek JC, Hurtado JE, Yang JH, et al. Efficacy and immunogenicity of unmodified and pseudouridinemodified mRNA delivered systemically with lipid nanoparticles in vivo. Biomaterials. 2016;109:78-87.

55. Behlke MA. Chemical modification of siRNAs for in vivo use. Oligonucleotides. 2008;18:305-19.

56. Fire A, Xu S, Montgomery MK, Kostas SA, Driver SE, Mello CC. Potent and specific genetic interference by double-stranded RNA in Caenorhabditis elegans. Nature. 1998;391:806-11.

57. McManus MT, Sharp PA. Gene silencing in mammals by small interfering RNAs. Nat Rev Genet. 2002;3:737-47.

58. Coelho T, Adams D, Silva A, Lozeron P, Hawkins PN, Mant T, et al. Safety and efficacy of RNAi therapy for transthyretin amyloidosis. N Engl J Med. 2013;369:819-29.

59. ClinicalTrials.gov. NCT01960348: APOLLO - The study of an investigational drug, patisiran (ALN-TTR02), for the treatment of transthyretin (TTR)mediated amyloidosis. https://clinicaltrials.gov/ct2/show/NCT01960348. Accessed 6 Mar 2017.

60. Suhr OB, Coelho T, Buades J, Pouget J, Conceicao I, Berk J, et al. Efficacy and safety of patisiran for familial amyloidotic polyneuropathy: a phase II multi dose study. Orphanet J Rare Dis. 2015;10:109.

61. Garber K. Alnylam terminates revusiran program, stock plunges. Nat Biotechnol. 2016;34:1213-4.

62. Manoharan M. GalNAc-siRNA with enhanced stabilization chemistry: ESC-GalNAc-siRNA. 2014. http://www.alnylam.com/2014/05/11/esc-galnacconjugates-tides2014/. Accessed 23 May 2017.

63. ClinicalTrials.gov. NCT01676259: a phase II study of siG12D LODER in combination with chemotherapy in patients with unresectable locally advanced pancreatic cancer. https://clinicaltrials.gov/ct2/show/ NCT01676259. Accessed 6 Mar 2017.

64. Golan T, Khvalevsky EZ, Hubert A, Gabai RM, Hen N, Segal A, et al. RNAi therapy targeting KRAS in combination with chemotherapy for locally advanced pancreatic cancer patients. Oncotarget. 2015;6: 24560-70.

65. Kleinman ME, Yamada K, Takeda A, Chandrasekaran V, Nozaki M, Baffi JZ, et al. Sequence- and target-independent angiogenesis suppression by siRNA via TLR3. Nature. 2008:452:591-7.

66. Askari FK, McDonnell WM. Antisense-oligonucleotide therapy. N Engl J Med. 1996:334:316-8

67. Agrawal S. Importance of nucleotide sequence and chemical modifications of antisense oligonucleotides. Biochim Biophys Acta Gene Struct Expr. 1999; 1489:53-67.

68. Chery J. RNA therapeutics: RNAi and antisense mechanisms and clinical applications. Postdoc J. 2016:4:35-50.

69. Young CS, Pyle AD. Exon skipping therapy. Cell. 2016;167:1144.

70. Liang X, Shen W, Sun H, Migawa MT, Vickers TA, Crooke ST. Translation efficiency of mRNAs is increased by antisense oligonucleotides targeting upstream open reading frames. Nat Biotechnol. 2016;34:1-8.

71. Crooke ST, Wang S, Vickers TA, Shen W, Liang X. Cellular uptake and trafficking of antisense oligonucleotides. Nat Biotechnol. 2017;35:230-7.

72. Dolgin E. Spinal muscular atrophy approval boosts antisense drugs. Nat Biotechnol. 2017;35:99-100

73. Mendell JR, Rodino-Klapac LR, Sahenk Z, Roush K, Bird L, Lowes LP, et al. Eteplirsen for the treatment of Duchenne muscular dystrophy. Ann Neurol. 2013;74:637-47.

74. Geary RS, Henry SP, Grillone LR. Fomivirsen. Clin Pharmacokinet. 2002;41: 255-60.

75. Merki E, Graham MJ, Mullick AE, Miller ER, Crooke RM, Pitas RE, et al. Antisense oligonucleotide directed to human apolipoprotein B-100 reduces lipoprotein(a) levels and oxidized phospholipids on human apolipoprotein B-100 particles in lipoprotein(a) transgenic mice. Circulation. 2008;118:743-53.

76. Raal FJ, Santos RD, Blom DJ, Marais AD, Charng MJ, Cromwell WC, et al. Mipomersen, an apolipoprotein B synthesis inhibitor, for lowering of LDL cholesterol concentrations in patients with homozygous familial hypercholesterolaemia: a randomised, double-blind, placebo-controlled trial. Lancet. 2010;375:998-1006
77. Becker LA, Huang B, Bieri G, Ma R, Knowles DA, Jafar-Nejad P, et al. Therapeutic reduction of ataxin-2 extends lifespan and reduces pathology in TDP-43 mice. Nature. 2017;544:367-71.

78. Scoles DR, Meera P, Schneider MD, Paul S, Dansithong W, Figueroa KP, et al. Antisense oligonucleotide therapy for spinocerebellar ataxia type 2. Nature. 2017:544:362-6.

79. Christopher A, Kaur R, Kaur G, Kaur A, Gupta V, Bansal P. MicroRNA therapeutics: Discovering novel targets and developing specific therapy. Perspect Clin Res. 2016;7:68.

80. Pereira DM, Rodrigues PM, Borralho PM, Rodrigues CMP. Delivering the promise of miRNA cancer therapeutics. Drug Discov Today. 2013;18:282-9.

81. Zhang Y, Wang Z, Gemeinhart RA. Progress in microRNA delivery. J Control Release. 2013;172:962-74.

82. Merhautova J, Vychytilova-Faltejskova P, Demlova R, Slaby O. Systemic administration of miRNA mimics by liposomal delivery system in animal model of colorectal carcinoma. Physiol Res. 2016;65(Supplementum 4): S481-8.

83. Li R-Q, Wu Y, Zhi Y, Yang X, Li Y, Xua F-J, et al. PGMA-based star-like polycations with plentiful hydroxyl groups act as highly efficient miRNA delivery nanovectors for effective applications in heart diseases. Adv Mater. 2016:28:7204-12.

84. Beg MS, Borad M, Sachdev J, Hong DS, Smith S, Bader A, et al. Abstract CT327: multicenter phase I study of MRX34, a first-in-class microRNA miR-34 mimic liposomal injection. Cancer Res. 2014;74(19 Supplement): CT327.

85. BusinessWire.com. Mirna therapeutics halts phase 1 clinical study of MRX34. 2016. http://www.businesswire.com/news/home/20160920006814/en/MirnaTherapeutics-Halts-Phase-1-Clinical-Study. Accessed 6 Mar 2017.

86. Wilczynska A, Bushell M. The complexity of miRNA-mediated repression. Cel Death Differ. 2015:22:22-33.

87. Mitragotri S, Burke PA, Langer R. Overcoming the challenges in administering biopharmaceuticals: formulation and delivery strategies. Nat Rev Drug Discov. 2014;13:655-72.

88. Tavernier G, Andries O, Demeester J, Sanders NN, De Smedt SC, Rejman J. mRNA as gene therapeutic: how to control protein expression. J Control Release. 2011;150:238-47.

89. Jemielity J, Fowler T, Zuberek J, Stepinski J, Lewdorowicz M, Niedzwiecka A, et al. Novel "anti-reverse" cap analogs with superior translational properties. RNA. 2003;9:1108-22.

90. Mockey M, Gonçalves C, Dupuy FP, Lemoine FM, Pichon C, Midoux P. mRNA transfection of dendritic cells: synergistic effect of ARCA mRNA capping with poly $(A)$ chains in cis and in trans for a high protein expression level. Biochem Biophys Res Commun. 2006;340:1062-8.

91. Strenkowska M, Grzela R, Majewski M, Wnek K, Kowalska J, Lukaszewicz M, et al. Cap analogs modified with 1,2-dithiodiphosphate moiety protect mRNA from decapping and enhance its translational potential. Nucleic Acids Res. 2016:44:9578-90.

92. Presnyak V, Alhusaini N, Chen Y, Martin S, Morris N, Kline N, et al. Codon optimality is a major determinant of mRNA stability. Cell. 2015:160:1111-24.

93. Thess A, Grund S, Mui BL, Hope MJ, Baumhof P, Fotin-Mleczek M, et al. Sequence-engineered mRNA without chemical nucleoside modifications enables an effective protein therapy in large animals. Mol Ther. 2015;23: 1456-64.

94. Holtkamp S, Kreiter S, Selmi A, Simon P, Koslowski M, Huber C, et al. Modification of antigen-encoding RNA increases stability, translational efficacy, and T-cell stimulatory capacity of dendritic cells. Blood. 2006;108: 4009-17.

95. Wroblewska L, Kitada T, Endo K, Siciliano V, Stillo B, Saito H, et al. Mammalian synthetic circuits with RNA binding proteins for RNA-only delivery. Nat Biotechnol. 2015;33:839-41.

96. Andries O, Mc Cafferty S, De Smedt SC, Weiss R, Sanders NN, Kitada T. N(1)-methylpseudouridine-incorporated mRNA outperforms pseudouridineincorporated mRNA by providing enhanced protein expression and reduced immunogenicity in mammalian cell lines and mice. J Control Release. 2015;217:337-44.

97. Svitkin YV, Cheng YM, Chakraborty T, Presnyak V, John M, Sonenberg N. N1methyl-pseudouridine in mRNA enhances translation through elF2adependent and independent mechanisms by increasing ribosome density. Nucleic Acids Res. 2017;45:6023-36.

98. Harcourt EM, Kietrys AM, Kool ET. Chemical and structural effects of base modifications in messenger RNA. Nature. 2017;541:339-46. 
99. Dowdy SF. Overcoming cellular barriers for RNA therapeutics. Nat Biotechnol. 2017;35:222-9.

100. Defrancesco L. The " anti-hype " vaccine. Nat Biotechnol. 2017;35:193-7.

101. Petsch B, Schnee M, Vogel AB, Lange E, Hoffmann B, Voss D, et al. Protective efficacy of in vitro synthesized, specific mRNA vaccines against influenza A virus infection. Nat Biotechnol. 2012;30:1210-6.

102. Karikó K, Buckstein M, Ni H, Weissman D. Suppression of RNA recognition by Toll-like receptors: the impact of nucleoside modification and the evolutionary origin of RNA. Immunity. 2005;23:165-75.

103. Allard SD, De Keersmaecker B, de Goede AL, Verschuren EJ, Koetsveld J, Reedijk ML, et al. A phase I/lla immunotherapy trial of HIV-1-infected patients with Tat, Rev and Nef expressing dendritic cells followed by treatment interruption. Clin Immunol. 2012;142:252-68.

104. Deering RP, Kommareddy S, Ulmer JB, Brito LA, Geall AJ. Nucleic acid vaccines: prospects for non-viral delivery of mRNA vaccines. Expert Opin Drug Deliv. 2014;11:1-15.

105. Ulmer JB, Geall AJ. Recent innovations in mRNA vaccines. Curr Opin Immunol. 2016;41:18-22.

106. Chahal JS, Khan OF, Cooper CL, McPartlan JS, Tsosie JK, Tilley LD, et al. Dendrimer-RNA nanoparticles generate protective immunity against lethal Ebola, H1N1 influenza, and Toxoplasma gondii challenges with a single dose. Proc Natl Acad Sci U S A. 2016;113:E4133-42.

107. Pardi N, Hogan MJ, Pelc RS, Muramatsu H, Andersen H, DeMaso CR, et al. Zika virus protection by a single low-dose nucleoside-modified mRNA vaccination. Nature. 2017;543:248-51.

108. Pardi N, Secreto AJ, Shan X, Debonera F, Glover J, Yi Y, et al. Administration of nucleoside-modified mRNA encoding broadly neutralizing antibody protects humanized mice from HIV-1 challenge. Nat Commun. 2017;8:14630.

109. Sullenger BA, Nair S. From the RNA world to the clinic. Science. 2016;352: 1417-20.

110. Oberli MA, Reichmuth AM, Dorkin JR, Mitchell MJ, Fenton OS, Jaklenec A, et al. Lipid nanoparticle assisted mRNA delivery for potent cancer immunotherapy. Nano Lett. 2017;17:1326-35.

111. Kranz LM, Diken M, Haas H, Kreiter S, Loquai C, Reuter KC, et al. Systemic RNA delivery to dendritic cells exploits antiviral defence for cancer immunotherapy. Nature. 2016;534:396-401.

112. Ramaswamy S, Tonnu N, Tachikawa K, Limphong P, Vega JB, Karmali PP, et al. Systemic delivery of factor IX messenger RNA for protein replacement therapy. Proc Natl Acad Sci U S A. 2017;114:E1941-50.

113. DeRosa F, Guild B, Karve S, Smith L, Love K, Dorkin JR, et al. Therapeutic efficacy in a hemophilia B model using a biosynthetic mRNA liver depot system. Gene Ther. 2016;23:699-707.

114. Kormann MSD, Hasenpusch G, Aneja MK, Nica G, Flemmer AW, Herber-jonat $\mathrm{S}$, et al. Expression of therapeutic proteins after delivery of chemically modified mRNA in mice. Nat Biotechnol. 2011;29:154-7.

115. Zangi L, Lui KO, von Gise A, Ma Q, Ebina W, Ptaszek LM, et al. Modified mRNA directs the fate of heart progenitor cells and induces vascular regeneration after myocardial infarction. Nat Biotechnol. 2013;31:898-907.

116. Pipeline-Cardiovascular Disease. https://www.modernatx.com/pipeline. Accessed 6 Jun 2017.

117. Cox DBT, Platt RJ, Zhang F. Therapeutic genome editing: prospects and challenges. Nat Med. 2015;21:121-31.

118. Chadwick AC, Musunuru K. Genome editing for the study of cardiovascular diseases. Curr Cardiol Rep. 2017;19:22.

119. Hu W, Kaminski R, Yang F, Zhang Y, Cosentino L, Li F, et al. RNA-directed gene editing specifically eradicates latent and prevents new HIV-1 infection. Proc Natl Acad Sci U S A. 2014;111:11461-6.

120. Thakore PI, Black JB, Hilton IB, Gersbach CA. Editing the epigenome: technologies for programmable transcription and epigenetic modulation. Nat Methods. 2016;13:127-37.

121. Sapranauskas R, Gasiunas G, Fremaux C, Barrangou R, Horvath P, Siksnys V. The Streptococcus thermophilus CRISPR/Cas system provides immunity in Escherichia coli. Nucleic Acids Res. 2011;39:9275-82.

122. Jinek M, Chylinski K, Fonfara I, Hauer M, Doudna JA, Charpentier E. A programmable dual-RNA-guided DNA endonuclease in adaptive bacterial immunity. Science. 2012;337:816-21.

123. Doudna JA, Charpentier E. The new frontier of genome engineering with CRISPR-Cas9. Science, 2014:346:1258096.

124. Rouet P, Smih F, Jasin M. Introduction of double-strand breaks into the genome of mouse cells by expression of a rare-cutting endonuclease. Mol Cell Biol. 1994;14:8096-106.
125. Cong L, Ran FA, Cox D, Lin S, Barretto R, Habib N, et al. Multiplex genome engineering using CRISPR/Cas systems. Science. 2013;339:819-23.

126. Dahlman JE, Abudayyeh OO, Joung J, Gootenberg JS, Zhang F, Konermann S. Orthogonal gene knockout and activation with a catalytically active Cas9 nuclease. Nat Biotechnol. 2015;33:1159-61.

127. Long C, Amoasii L, Mireault AA, McAnally JR, Li H, Sanchez-Ortiz E, et al. Postnatal genome editing partially restores dystrophin expression in a mouse model of muscular dystrophy. Science. 2016;351:400-3.

128. Nelson CE, Hakim CH, Ousterout DG, Thakore PI, Moreb EA, Castellanos Rivera RM, et al. In vivo genome editing improves muscle function in a mouse model of Duchenne muscular dystrophy. Science. 2016;351:403-7.

129. Tabebordbar M, Zhu K, Cheng JKW, Chew WL, Widrick JJ, Yan WX, et al. In vivo gene editing in dystrophic mouse muscle and muscle stem cells. Science. 2016;351:407-11.

130. Yin H, Xue W, Chen S, Bogorad RL, Benedetti E, Grompe M, et al. Genome editing with Cas 9 in adult mice corrects a disease mutation and phenotype. Nat Biotechnol. 2014;32:551-3.

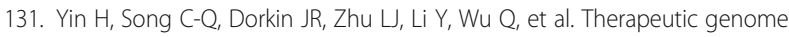
editing by combined viral and non-viral delivery of CRISPR system components in vivo. Nat Biotechnol. 2016;34:328-33.

132. Yang Y, Wang L, Bell P, McMenamin D, He Z, White J, et al. A dual AAV system enables the Cas9-mediated correction of a metabolic liver disease in newborn mice. Nat Biotechnol. 2016:34:334-8.

133. Ding Q, Strong A, Patel KM, Ng SL, Gosis BS, Regan SN, et al. Permanent alteration of PCSK9 with in vivo CRISPR-Cas9 genome editing. Circ Res. 2014;115:488-92.

134. Fellmann C, Gowen BG, Lin P-C, Doudna JA, Corn JE. Cornerstones of CRISPR-Cas in drug discovery and therapy. Nat Rev Drug Discov. 2016;16: 89-100.

135. Tycko J, Myer VE, Hsu PD. Methods for optimizing CRISPR-Cas9 genome editing specificity. Mol Cell. 2016;63:355-70.

136. Komor AC, Badran AH, Liu DR. CRISPR-based technologies for the manipulation of eukaryotic genomes. Cell. 2016;168:1-17.

137. Moreno AM, Mali P. Therapeutic genome engineering via CRISPR-Cas systems. Wiley Interdiscip Rev Syst Biol Med. 2017:e1380. doi: 10.1002/ wsbm.1380

138. Fu Y, Sander JD, Reyon D, Cascio VM, Joung JK. Improving CRISPR-Cas nuclease specificity using truncated guide RNAs. Nat Biotechnol. 2014;32: $279-84$.

139. Moreno-Mateos MA, Vejnar CE, Beaudoin J, Fernandez JP, Mis EK, Khokha MK, et al. CRISPRscan: designing highly efficient sgRNAs for CRISPR-Cas9 targeting in vivo. Nat Methods. 2015;12:982-8.

140. Hendel A, Bak RO, Clark JT, Kennedy AB, Ryan DE, Roy S, et al. Chemically modified guide RNAs enhance CRISPR-Cas genome editing in human primary cells. Nat Biotechnol. 2015;33:985-9.

141. Kleinstiver BP, Pattanayak V, Prew MS, Tsai SQ, Nguyen NT, Zheng Z, et al. High-fidelity CRISPR-Cas9 nucleases with no detectable genome-wide offtarget effects. Nature. 2016;529:490-5.

142. Slaymaker IM, Gao L, Zetsche B, Scott DA, Yan WX, Zhang F. Rationally engineered Cas9 nucleases with improved specificity. Science. 2016;351:84-8.

143. Zetsche B, Gootenberg JS, Abudayyeh OO, Slaymaker IM, Makarova KS, Essletzbichler P, et al. Cpf1 is a single RNA-guided endonuclease of a class 2 CRISPR-Cas system. Cell. 2015:163:759-71.

144. Zetsche B, Heidenreich M, Mohanraju P, Fedorova I, Kneppers J, DeGennaro EM, et al. Multiplex gene editing by CRISPR-Cpf1 using a single crRNA array. Nat Biotechnol. 2016;35:31-4

145. Zuris JA, Thompson DB, Shu Y, Guilinger JP, Bessen JL, Hu JH, et al. Cationic lipid-mediated delivery of proteins enables efficient protein-based genome editing in vitro and in vivo. Nat Biotechnol. 2014;33:73-80.

146. Richardson CD, Ray GJ, DeWitt MA, Curie GL, Corn JE. Enhancing homology-directed genome editing by catalytically active and inactive CRISPR-Cas9 using asymmetric donor DNA. Nat Biotechnol. 2016;34: $339-44$.

147. Vartak SV, Raghavan SC. Inhibition of nonhomologous end joining to increase the specificity of CRISPR/Cas9 genome editing. FEBS J. 2015;282: 4289-94.

148. Robert F, Barbeau M, Éthier S, Dostie J, Pelletier J. Pharmacological inhibition of DNA-PK stimulates Cas9-mediated genome editing. Genome Med. 2015; 7:93.

149. Song J, Yang D, Xu J, Zhu T, Chen YE, Zhang J. RS-1 enhances CRISPR/Cas9and TALEN-mediated knock-in efficiency. Nat Commun. 2016;7:10548. 
150. Suzuki K, Tsunekawa Y, Hernandez-Benitez R, Wu J, Zhu J, Kim EJ, et al. In vivo genome editing via CRISPR/Cas9 mediated homology-independent targeted integration. Nature. 2016;540:144-9.

151. Stewart MP, Sharei A, Ding $X$, Sahay G, Langer $R$, Jensen KF. In vitro and ex vivo strategies for intracellular delivery. Nature. 2016;538:183-92.

152. Oude Blenke E, Evers MJW, Mastrobattista E, van der Oost J. CRISPR-Cas9 gene editing: delivery aspects and therapeutic potential. J Control Release. 2016;244:139-48.

153. Mingozzi F, High KA. Therapeutic in vivo gene transfer for genetic disease using AAV: progress and challenges. Nat Rev Genet. 2011;12:341-55.

154. Chew WL, Tabebordbar M, Cheng JKW, Mali P, Wu EY, Ng AHM, et al. A multifunctional AAV-CRISPR-Cas9 and its host response. Nat Methods. 2016;13:868-74

155. Yin H, Kanasty RL, Eltoukhy AA, Vegas AJ, Dorkin JR, Anderson DG. Non-viral vectors for gene-based therapy. Nat Rev Genet. 2014;15:541-55.

156. Mahiny AJ, Dewerth A, Mays LE, Alkhaled M, Mothes B, Malaeksefat E, et al. In vivo genome editing using nuclease-encoding mRNA corrects SP-B deficiency. Nat Biotechnol. 2015;33:584-6.

157. Miller JB, Zhang S, Kos P, Xiong H, Zhou K, Perelman SS, et al. Non-viral CRISPR/Cas gene editing in vitro and in vivo enabled by synthetic nanoparticle co-delivery of Cas9 mRNA and sgRNA. Angew Chemie Int Ed. 2017:56:1059-63.

158. Mout R, Ray M, Yesilbag Tonga G, Lee Y-W, Tay T, Sasaki K, et al. Direct cytosolic delivery of CRISPR/Cas9-ribonucleoprotein for efficient gene editing. ACS Nano. 2017;11:2452-8.

159. Wang M, Zuris JA, Meng F, Rees $H$, Sun S, Deng $P$, et al. Efficient delivery of genome-editing proteins using bioreducible lipid nanoparticles. Proc Natl Acad Sci U S A. 2016;113:2868-73.

160. Chi X, Gatti P, Papoian T. Safety of antisense oligonucleotide and siRNAbased therapeutics. Drug Discov Today. 2017;22:823-33.

161. Wolinetz CD. Emerging biotechnologies and the role of the NIH RAC. 2016. https://perma.cc/NWF7-UXXF. Accessed 25 May 2017.

162. CRISPR Therapeutics. http://www.crisprtx.com. Accessed 9 Jun 2017.

163. Editas Medicine. http://www.editasmedicine.com. Accessed 9 Jun 2017.

164. Intellia Therapeutics. http://www.intelliatx.com. Accessed 9 Jun 2017. 